\title{
SLIDING MODE CONTROL WITH DIFFERENT SLIDING SURFACES A COMPARISON ON SPEED CONTROL OF INDUCTION MOTOR
}

\author{
Jisha L K $\mathbf{K}^{1}$, A A Powly Thomas ${ }^{2}$, Suresh Srivastava ${ }^{3}$ \\ ${ }^{I}$ Department of Electrical \& Electronics Engineering, Sri Venkateshwara College of Engineering, Bangalore. \\ jisha_lk@hotmail.com \\ ${ }^{2}$ Gopalan College of Engineering \& Management, Bangalore. \\ ${ }^{3}$ O/o Director General - Aeronautics, DRDO, Bangalore.
}

\begin{abstract}
In this paper closed loop speed control of vector controlled Induction motor is described. Sliding Mode Controller (SMC) is used to get the better performance for the closed loop system in the presence of uncertainties and load disturbances. A comparative study is done on Sliding Mode Controller with different sliding surfaces. The sliding surfaces are designed based on PI and PID controllers. The simulation of the closed loop system is done using MATLAB / Simulink and the results are compared. The simulation results verify that the performance of PID based sliding surface is superior compared to that of PI based sliding surfaces.
\end{abstract}

Keywords: Sliding Mode Control, Induction Motor, Sliding Surface, PID.

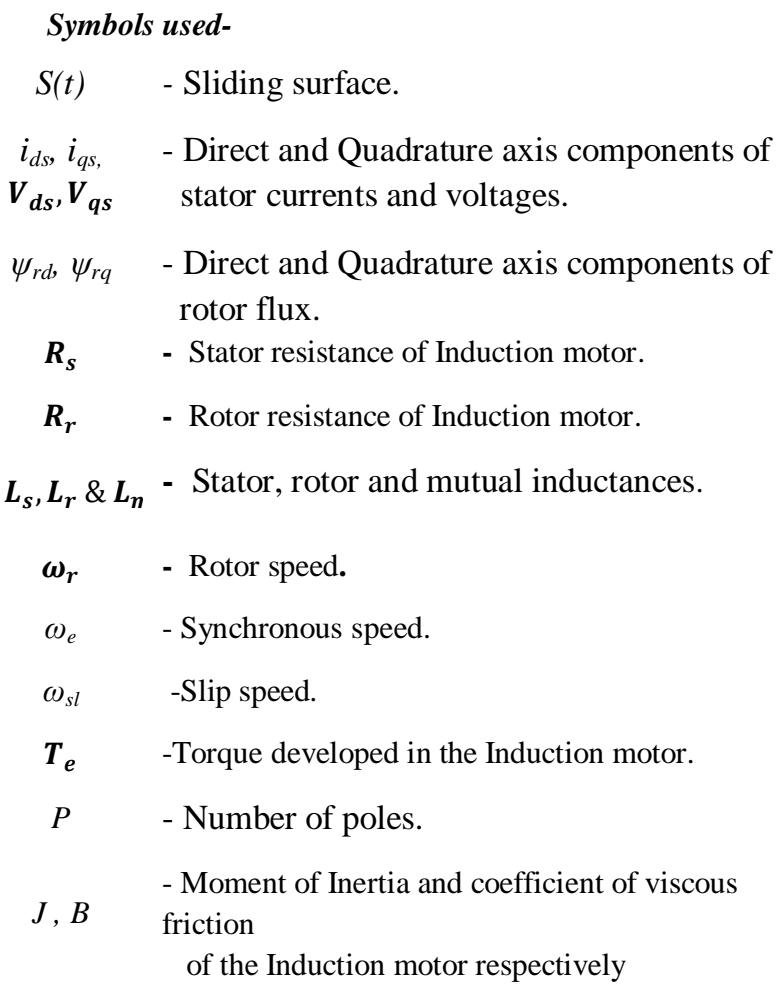

\section{INTRODUCTION}

Due to the innovations in Power Electronics, DSPs and Micro controllers, in recent years the variable speed applications are dominated by Induction motor drives. By the introduction of vector control or field oriented control (FOC) which is based on the orientation of rotor flux, applied to the Induction motor provides the decoupling between torque and flux [1]. This property of vector control promised that the Induction motor can be controlled as easy as separately excited DC motor. In addition to this Induction motor offers many attractive features such as small size, less cost, low maintenance and better efficiency compared to other motors.

In last few decades the PID controllers were extensively used as the controller for the vector control of induction motors due to its good performance, simple structure and easy implementation. But the performance of the system with PID controller is still influenced by the uncertainties which can happen due to external load disturbances, unpredictable parameter variations, and nonlinear dynamics. Therefore many studies have been done in order to maintain the better performance of Induction motor in the presence of uncertainties such as adaptive control, Variable Structure control, fuzzy and neural control etc $[4,5,8]$.

Nowadays, the Sliding Mode Controller which is a variable structure control has attracted more attention in the area of control of electrical drives [2]. The Sliding Mode Controller is a variable structure control technique with excellent features like accuracy, robustness, superior dynamic performance and easy implementation. The design of SMC involves two steps. The step one is to select the suitable sliding surface $S(t)$ in terms of tracking error and step two is the design of control signal $u(t)$.

In this paper Sliding Mode Controller is applied for the speed control of Indirect Field Oriented Induction motor. The sliding mode controller is designed with two different sliding surfaces and a comparative study is done to study the behavior of the system with different sliding surfaces. The performance of both the Sliding Mode Controllers are compared with that of PID controller. 


\section{VECTOR CONTROLLED INDUCTION}

\section{MOTOR MODEL}

The mathematical model of the vector controlled Induction motor in synchronously rotating $\mathrm{d}-\mathrm{q}$ reference frame is given below [4]. The state variables selected are

isd, isq, $\psi r d, \psi r q$.

$$
\begin{gathered}
\frac{d i_{s d}}{d t}=-\left(\frac{R_{s}}{\sigma L_{s}}+\frac{1-\sigma}{\sigma \tau_{r}}\right) i_{s d}+\omega_{e} i_{s q}+\frac{L_{m}}{\sigma L_{s} L_{r} \tau_{r}} \psi_{r d} \\
\quad+\frac{L_{m} \omega_{r}}{\sigma L_{s} L_{r}} \psi_{r q}+\frac{1}{\sigma L_{s}} V_{s d} \\
\frac{d i_{s q}}{d t}=-\left(\frac{R_{s}}{\sigma L_{s}}+\frac{1-\sigma}{\sigma \tau_{r}}\right) i_{s q}+\omega_{e} i_{s d}+\frac{L_{m}}{\sigma L_{s} L_{r} \tau_{r}} \psi_{r q} \\
\quad+\frac{L_{m} \omega_{r}}{\sigma L_{s} L_{r}} \psi_{r d}+\frac{1}{\sigma L_{s}} V_{s q} \\
\frac{d \psi_{r d}}{d t}=\frac{L_{m}}{\tau_{r}} i_{s d}+\frac{1}{\tau_{r}} \psi_{r d}+\left(\omega_{e}-\omega_{r}\right) \psi_{r q} \\
\frac{d \psi_{r q}}{d t}=\frac{L_{m}}{\tau_{r}} i_{s q}-\frac{1}{\tau_{r}} \psi_{r q}-\left(\omega_{e}-\omega_{r}\right) \psi_{r d} \\
T_{e}=\frac{3 P}{4} \frac{L_{m}}{L_{r}}\left(\psi_{r d} i_{s q}-\psi_{r q} i_{s d}\right)
\end{gathered}
$$

$\sigma=1-\frac{L_{m}^{2}}{L_{s} L_{r}}$ is the leakage coefficient of flux.

$\tau_{r}=\frac{L_{r}}{R_{r}}$ is the rotor time constant.

In the field oriented control, for decoupling of torque and flux, $i_{s q}$ should be oriented in the direction of flux $\psi_{r}$ and $i_{s d}$ should be perpendicular to it. Then current $i_{s}$ can be controlled by means of $i_{s q}$ without affecting flux $\psi_{r}$ and $\psi_{r}$ is controlled by means of $i_{s d}$ without affecting the current $i_{s q}$.

This condition is met if $\psi_{r q}=0$,

then, $\psi_{r d}=\psi_{r}$

Then the above equations are simplified to

$$
\begin{gathered}
\frac{d i_{s d}}{d t}=-\left(\frac{R_{s}}{\sigma L_{s}}+\frac{1-\sigma}{\sigma \tau_{r}}\right) i_{s d}+\omega_{e} i_{s q}+\frac{L_{m}}{\sigma L_{s} L_{r} \tau_{r}} \psi_{r d} \\
+\frac{1}{\sigma L_{s}} V_{s d} \\
\frac{d i_{s q}}{d t}=-\left(\frac{R_{s}}{\sigma L_{s}}+\frac{1-\sigma}{\sigma \tau_{r}}\right) i_{s q}+\omega_{e} i_{s d}+ \\
+\frac{L_{m} \omega_{r}}{\sigma L_{s} L_{r}} \psi_{r d}+\frac{1}{\sigma L_{s}} V_{s q} \\
\frac{d \psi_{r d}}{d t}=\frac{L_{m}}{\tau_{r}} i_{s d}+\frac{1}{\tau_{r}} \psi_{r d} \\
0=\frac{L_{m}}{\tau_{r}} i_{s q}-\left(\omega_{e}-\omega_{r}\right) \psi_{r d}
\end{gathered}
$$

$$
\begin{gathered}
T_{e}=\frac{3 P}{4} \frac{L_{m}}{L_{r}}\left(\psi_{r d} i_{s q}\right) \\
T_{e}=K_{T} i_{s q}
\end{gathered}
$$

Where

$$
K_{T}=\frac{3 P}{4} \frac{L_{m}}{L_{r}} \psi_{r d}^{*}
$$

Where $\psi_{r d}^{*}$ is the command rotor flux.

From (2), $\omega_{s l}=\omega_{e}-\omega_{r}=\frac{L_{m}}{\tau_{r}} \frac{i_{s q}}{\psi_{r d}}$

In Indirect Field Oriented Control the slip speed $\omega_{s l}$ thus obtained is added with the rotor speed $\omega_{r}$ to generate synchronous speed $\omega_{e}$ which is then integrated to obtain $\theta_{e}$. The unit vectors $\cos \theta_{e}$ and $\sin \theta_{e}$ are obtained from $\theta_{e}$.

\section{SLIDING MODE CONTROLLER}

In recent years sliding mode control has emerged because of its robustness in the presence of uncertainties and its simplicity in implementation [3]. In Induction motors the parameter variations can happen due to the winding resistance variations because of temperature changes, switching effect of converters, unexpected load variations etc. The SMC technique based on variable structure control provides a smooth robust control approach for Induction motor with order reduction, disturbance rejection with systematic and easy implementation procedures.

The first step in the design of SMC is to select the suitable sliding surface $S(t) . S(t)$ is constructed by the linear combination of the state variables and usually for tracking problems the error $e(t)$ is chosen as variable as at steady state the variable should become zero.

The typical choice of $S(t)$ is ,

$$
S=\lambda e+\dot{e}
$$

Where e is the tracking error, $e=\omega_{m}-\omega_{m}^{*}$

Where $\omega_{m}$ is the mechanical speed of rotor in $\mathrm{rad} / \mathrm{sec}$, $\omega_{m}^{*}$ is the reference rotor speed, $\lambda$ is a positive constant When the trajectory reaches sliding surface tracking error converges to zero as long as error vector stays on the sliding

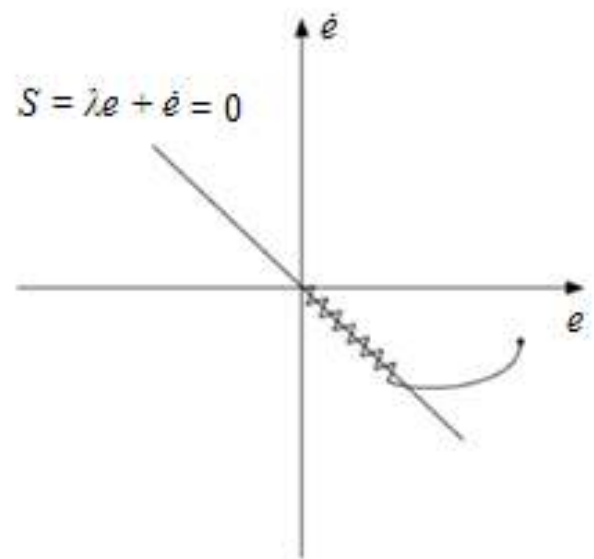

Fig 1. Phase trajectory of the system with SMC. 
surface. Figure 1 shows the mechanism that happens in phase plane. There are two modes in the sliding mode approach. The first mode called reaching mode in which the phase trajectory $(e, \dot{e})$ is attracted towards the switching surface $S=0$. In the second mode known sliding mode, the phase trajectory slides on the surface until it reaches the equilibrium point $(0,0)$

After choosing the sliding surface the next step is to obtain the control law $u(t)$ that will allow the error vector $(e, \dot{e})$ to reach the sliding surface .

For that the control law should be designed in such a way that the condition,

$S . \dot{S}<0, \forall \mathrm{t}$

is met. The above condition is called reaching law.

In order to satisfy the above condition, in SMC, $\dot{S}$ is typically chosen as

$\dot{S}=-\varepsilon \operatorname{Sign}(S), \forall \mathrm{t}, \quad \varepsilon>0$

The term $-\varepsilon$ will force the system state towards the sliding surface rapidly. Therefore higher value of $\varepsilon$ will reduce the time of reaching mode. But larger value of $\varepsilon$ induces the phenomena called chattering. Chattering may excite unmodelled high frequency oscillations in the control signal which leads to high control activity, deterioration of moving parts and heat losses in electric power circuit.

The torque equation of the Induction motor is given by

$$
T_{e}=J \dot{\omega}_{m}+B \omega_{m}+T_{L}
$$

$J$ and $B$ are the Moment of Inertia and coefficient of viscous friction of the Induction motor respectively. $T_{L}$ is the external load applied to the Induction motor. $\omega_{m}$ is the rotor mechanical speed and is related with rotor electrical speed $\omega_{r}$ by the equation,

$$
\omega_{m}=\frac{2 \omega_{r}}{P}
$$

$T_{e}$ is torque generated by the Induction motor.

Equating (3) and (10) we get,

$$
J \dot{\omega}_{m}+B \omega_{m}+T_{L}=K_{T} i_{s q}
$$

As per (4) $i_{s q}$ is the control signal $u(t)$ which controls the rotor speed.

\section{Case 1. Design of Sliding Mode Controller 1 (SMC1)}

In SMC1 the sliding surface selected is based on PID controller. An integral term is added with (5) which reduces the steady state error.

$S(t)=k_{1} e+k_{2} \dot{e}+k_{3} \int e d t$
Where $k_{1}, k_{2}$ and $k_{3}$ are constants

Differentiating (12),

$$
\begin{aligned}
& \dot{S(t)}=k_{1} \dot{e}+k_{2} \ddot{e}+k_{3} e \\
& \text { Where } \dot{\mathrm{e}}=\omega_{m}-\omega_{m}^{*}, \ddot{\mathrm{e}}=\ddot{\omega}_{m}-\ddot{\omega}_{m}^{*}
\end{aligned}
$$

$\dot{\omega}_{m}^{*}, \ddot{\omega}_{m}^{*}$ are zero as the reference speed is considered as constant.

Equating (8) and (13) and using (11) and (14),

$$
\begin{aligned}
& i_{s q}=\left(-\varepsilon \operatorname{Sign}(S)-k_{2} \ddot{\omega}_{m}+\frac{k_{1} B}{J} \omega_{m}+\frac{k_{1}}{J} T_{L}+\right. \\
& k 3 e / k 1 K T
\end{aligned}
$$

It is seen that the control signal $u=i_{s q}$ has two parts, equivalent control and discontinuous control.

$$
\begin{aligned}
& u=u_{e q}+u_{\text {disc }} \\
& u_{e q}=\left(-k_{2} \ddot{\omega_{m}}+\frac{k_{1} B}{J} \omega_{m}+\frac{k_{1}}{J} T_{L}+k_{3} e\right) \frac{J}{k_{1} K_{T}} \\
& u_{\text {disc }}=-\varepsilon \operatorname{Sign}(S) \frac{J}{k_{1} K_{T}}
\end{aligned}
$$

The discontinuous control which has signum function $(\operatorname{sign}()$.$) is responsible for chattering.$

\section{Case 2. Design of Sliding Mode Controller 2 (SMC2)}

In SMC2 the sliding surface selected is based on PI controller.

$S(t)=e+\int(a+k) e d t$

Where $a$ and $k$ are positive constants

Differentiating (12),

$$
\dot{S}(t)=\dot{e}+(a+k) e d t
$$

Equating (8) and (19) and using (11) and (14),

$$
\begin{gathered}
i_{s q}=\left(-\varepsilon \operatorname{Sign}(S)+\frac{B}{J} \omega_{m}+\frac{1}{J} T_{L}-(a+k)\right) \frac{J}{K_{T}} \\
u_{e q}=\left(\frac{B}{J} \omega_{m}+\frac{1}{J} T_{L}-(a+k)\right) \frac{J}{K_{T}} \\
u_{\text {disc }}=-\varepsilon \operatorname{Sign}(S) \frac{J}{K_{T}}
\end{gathered}
$$

Figure 2 shows the block diagram representation of the Sliding Mode Controlled Indirect Field Oriented Induction motor. 


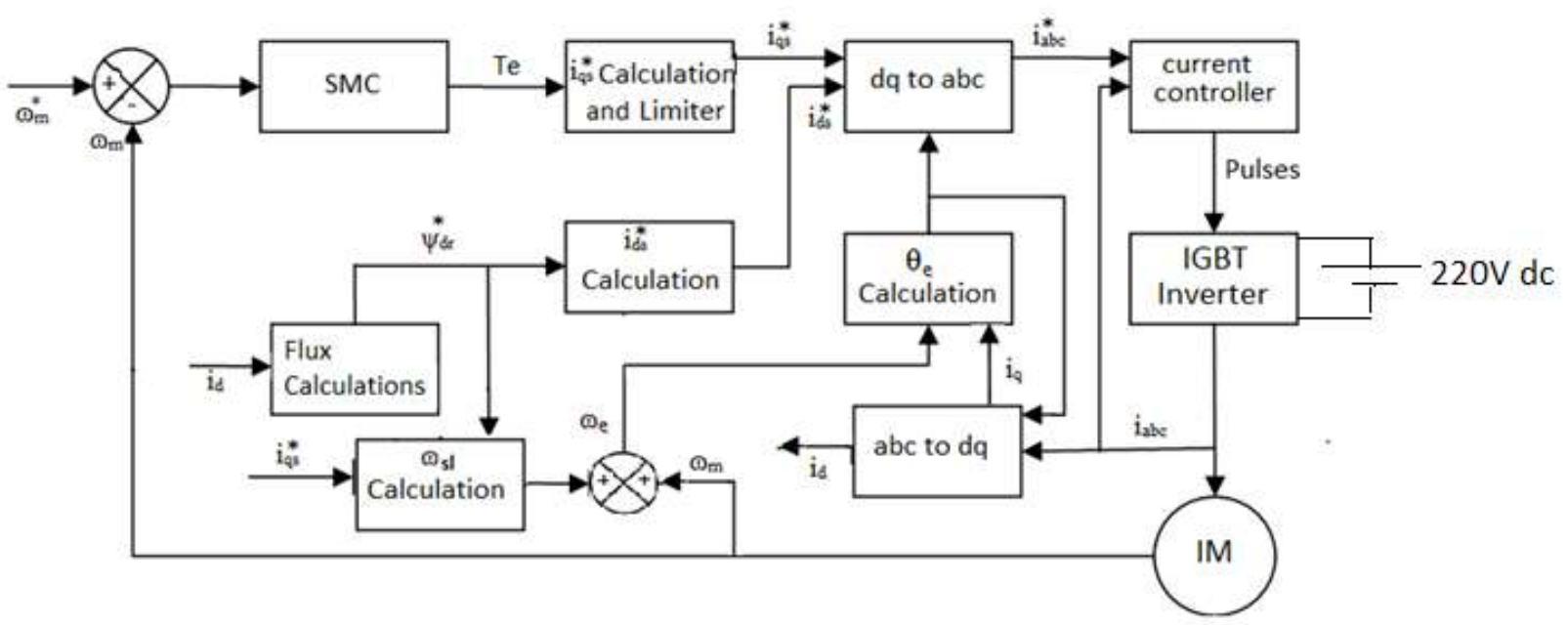

Fig 2. Block diagram representation of the system with SMC

The system is supplied with $220 \mathrm{~V} \mathrm{dc}$ and a 2 level IGBT inverter is used. The triggering pulses are obtained from hysteresis current controller.

\section{SIMULATION RESULTS}

The simulation of the controllers are done on 1HP

(746W), 220V, 5A, 4 pole squirrel cage induction motor. The simulation is done with SMC1, SMC2 and PID controller. For simulation MATLAB 7.10(R2010a) /SIMULINK is used. Powergui tool in simpower systems toolbox is used. Figure 3, 4, 5, 6 and 7 show the simulation results of the proposed controllers.

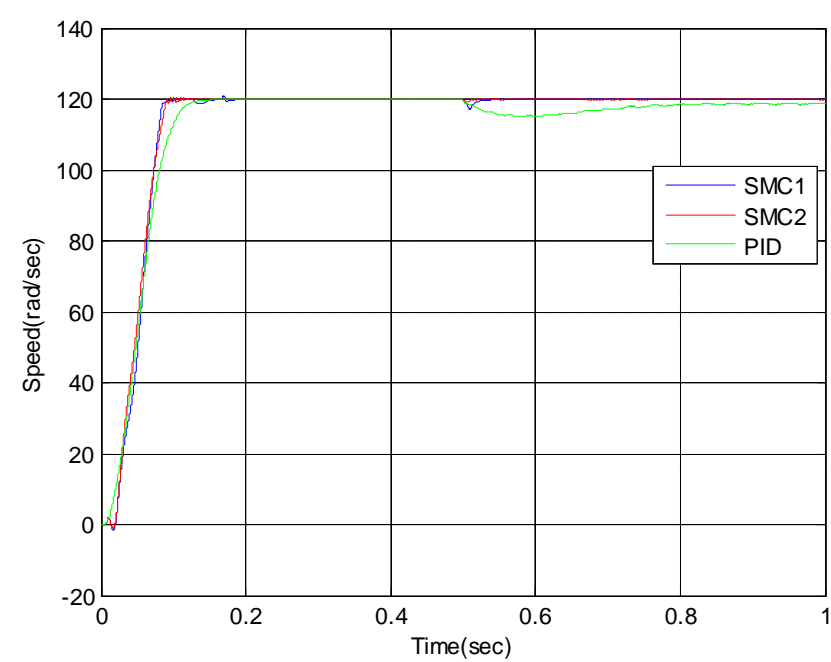

Fig 3. Speed - Time response of PID, SMC1 and SMC2 applying external load after 0.5 secs.

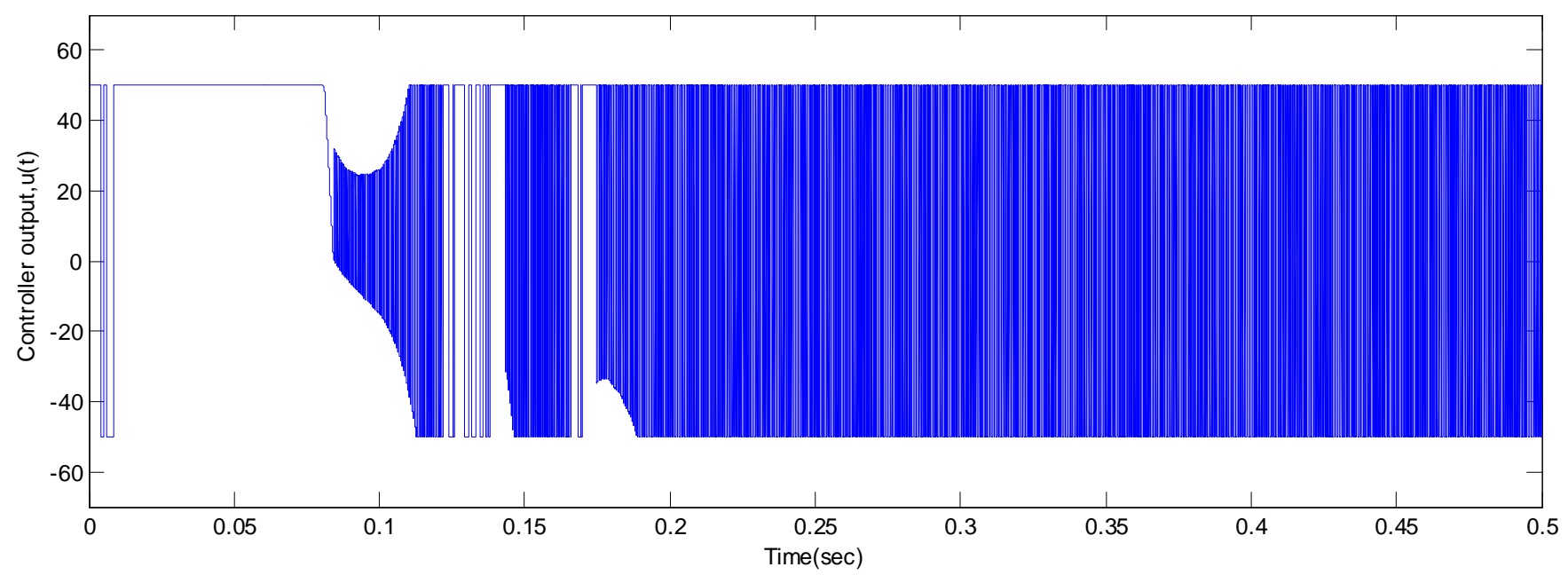

Fig 4. Control signal with SMC1 


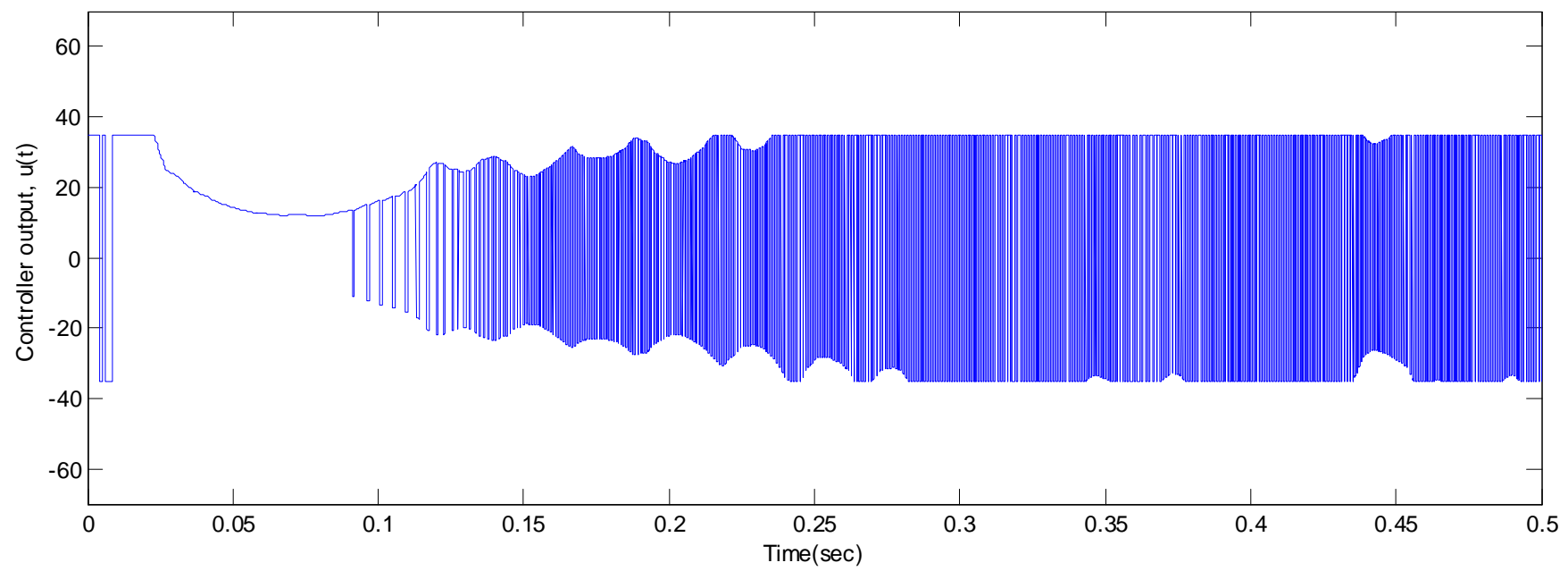

Fig 5. Control signal with SMC2

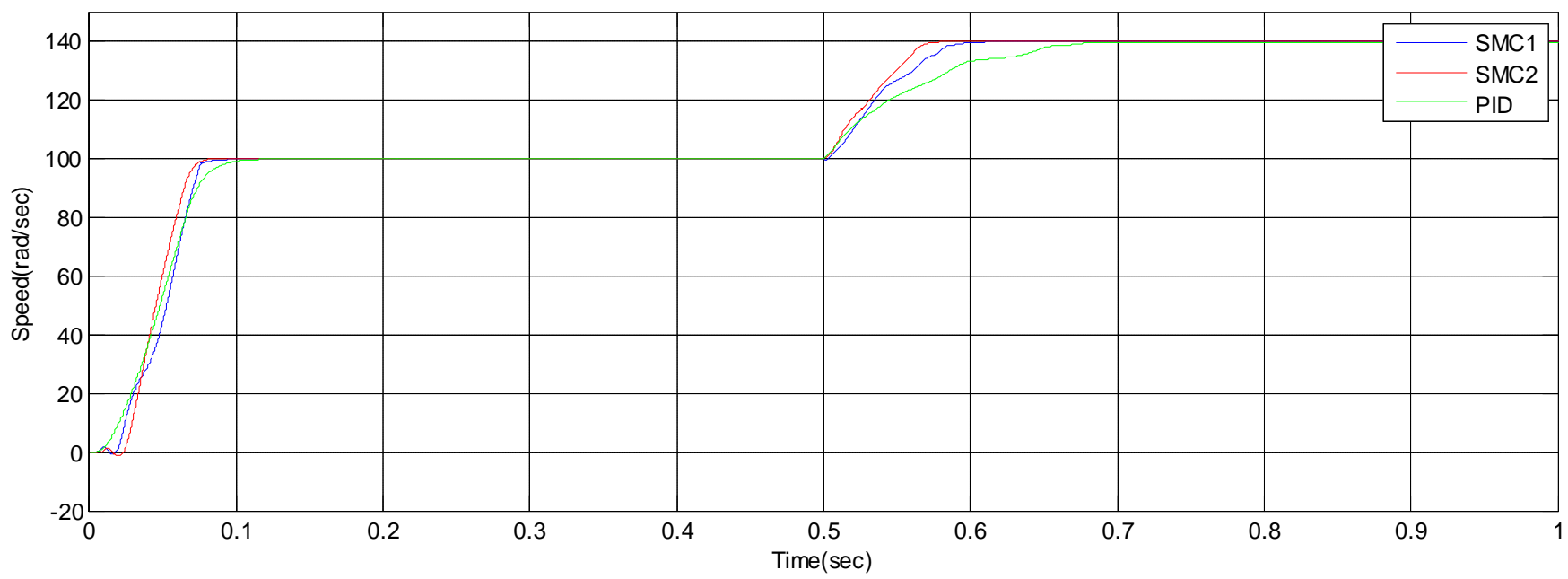

Fig6. Speed - Time response of PID, SMC1 and SMC2 when applied a step change in reference speed after 0.5 secs.

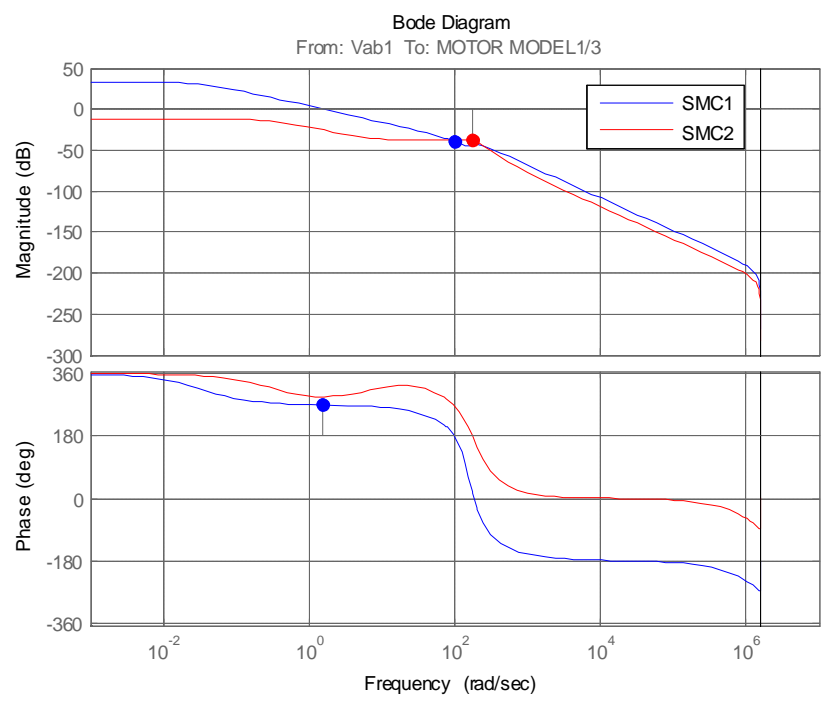

Fig 7. Frequency response of SMC1 and SMC2 controllers

Figure3 shows the Speed - Time response of PID, SMC1 and SMC2 with applying external load. It is seen that the risetime of PID is more compared to that of Sliding Mode
Controllers. Compared to SMC1, SMC2 performance is better at the moment of application of load. Figure 4 and 5 show the control input required for SMC1 and SMC2. It is seen that SMC1 higher magnitude of control input compared to that of SMC2. The chattering of control signal is less in SMC2 compared to that of SMC1. Figure 6 shows the speed - time response of SMC1, SMC2 and PID controller when there is a sudden change in reference speed from $100 \mathrm{rad} / \mathrm{sec}$ to $140 \mathrm{rad} / \mathrm{sec}$. It is seen that speed tracking of SMC is superior than that of PID controllers. Among SMC, tracking of SMC2 is fast and smooth compared to that of SMC1. Figure 7 show the frequency response of SMC1 and SMC2. It is seen that stability of the system with SMC1 is better than that of SMC2.

\section{CONCLUSION}

In this paper closed loop speed control for vector controlled induction motor with Sliding Mode Controller is described. SMC is implemented in two different methods, using different functions as sliding surfaces, SMC1 and SMC2. The performance of both the controllers and PID controller are simulated and compared. As usual performance of SMC 
in the presence of load variations and other disturbances are superior compared to that of PID. Among SMC1and SMC2 the time response of SMC2 is better, but in the stability aspects SMC1 is superior. Chattering phenomena in SMC2 is less compared to that of SMC1.

\section{REFERENCES}

[1]. Bimal.K.Bose, "Modern Power Electronics and AC Drives", Prentice Hall of India Private Limited, 2008.

[2]. U.I.Utkin,"Sliding mode control design principles and applications to electric drives",IEEE transactions on industrial Electronics, vol 40, pp 26-36, 1993.

[3]. Oscar Barambones, Patxi Alkorta, Jose Maria Gonzalez De Durana, "Sliding Mode Position Control for Real Time Control of Induction Motor", International Journal of Innovative Computing, Information and Control, Vol. 9 July 2013.

[4]. Oscar Barambones, Patxi Alkorta, Jose Maria Gonzalez De Durana, "An adaptive sliding mode control scheme for induction motor drives", International Journal of Circuits, Systems and Signal processing, Vol. 1 Jan 2007.

[5]. Dramane Traore, Frank Plestan, Alain Glumineau, "High-Order Sliding - Mode Controller and adaptive Interconnected Observer", IEEE transactions on industrial Electronics, vol 55, No 11, November 2008

[6]. Hardik A Shah, Amit Patel, Rakesh Patel, "Controller Design via Sliding Mode Control approach of Induction Motor - A Survey", Fourth International Conference on Advanced Computing and Communication Technologies, 2014.

[7]. K. Jamoussi L, Chrifi-Alaoui H, Benderradji A, El Hajjaji, M. Ouali," Robust Sliding Mode Control Using Adaptive Switching Gain for Induction Motors", International Journal of Automation and Computing 10(4), August 2013, 303-31 